\title{
Review of COVID-19 vaccinated patients' emergency room admissions
}

\author{
๑Ensar Durmuş, @Necip Gökhan Güner, @Fatih Güneysu, @Nuray Aslan, @Yusuf Yürümez \\ Sakarya University Training and Research Hospital,Department of Emergency Service, Sakarya, Turkey
}

Cite this article as: Durmuş E, Güner NG, Güneysu F, Aslan N, Yürümez Y. Review of COVID-19 vaccinated patients' emergency room admissions. J Health Sci Med 2022; 5(1): 18-21.

\begin{abstract}
Introduction: This study was aimed to define the demographic structure of vaccinated patients admitted to the emergency room (ER) with COVID-19 symptoms, and their hospitalization status, length of stay (LoS) in hospital, and mortality status.

Material and Method: This research is a retrospective, cross-sectional and descriptive study. Furthermore, it includes the period between 15.01.2021 and 30.04.2021.

Results: An 887 COVID-19 vaccinated patients who applied to ER. Of these, 383 (42.2\%) were male, and 504 (56.8\%) were female. The mean age of the patients was $52 \pm 18.6$ years. The number of single-dose vaccinated patients was $696(78.5 \%)$, and the two-dose vaccinated was 191 (21.5\%). CoronaVac (Sinovac Life Sciences) vaccine was applied to 755 (85.1\%), and BNT162b2 (Pfizer \& Biontech) vaccine was applied to 132 (14.9\%) patients before.

In 317 (35.7\%) cases, reverse transcription-polymerase chain reaction (Rt-PCR) positivity was detected in the ER application after vaccination. Of the total patients, 86 (9.7\%) were hospitalized, 14 (1.4\%) patients died in the hospital.

The mean time between vaccination and application to ER was $25( \pm 21.9)$ days. Also, this period was 28.1 ( \pm 18$)$ days in twodose vaccinated patients.

Conclusion: People who are vaccinated with the COVID-19 vaccine continue to have hospital admissions with COVID-19 symptoms. Rt-PCR positivity, need for hospitalization, and mortality may continue to be seen in vaccinated individuals.
\end{abstract}

Keywords: Pandemic, COVID-19, vaccine, emergency room

\section{INTRODUCTION}

Since the World Health Organization (WHO) declared the COVID-19 pandemic in March 2020, health officials have been looking for a method to combat this disease (1). On the one hand, measures were taken to reduce the spread of the virus, such as social isolation, wearing masks, public transportation regulations, and curfew; on the other hand, investigations were conducted to treat infected cases $(2,3)$. Although many drugs have been used to manage the disease in the early days, there is still no definitive method to treat the infection (4).

The high mortality rate in hospitalized patients, the long hospitalization period of the patients, the significant rate of patients in need of intensive care, and the extensive mortality have pointed that other resolutions should be queried. As a solution, COVID-19 vaccine research has been initiated globally and has progressed rapidly (5).

It is unknown exactly what effect the mutant viruses will have on vaccines when the SARS-CoV-2 virus mutates
(6). It is troubling that the progress in potential virus pathogenicity due to mutations will create challenges in drug and vaccine improvement levels (7). On the other hand, a suitable vaccine is demanded to help fight disease; furthermore, especially to have a protective effect against severe diseases and mortality (8).

Vaccination programs against COVID-19 have commenced in Turkey since January/2021. In the first place, healthcare workers, immunosuppressed patients, cancer patients, and the elderly population were vaccinated with the inactive CoronaVac vaccine (Sinovac Life Sciences). Later, mRNA vaccines BNT162b2 (Pfizer\& Biontech) were added to the vaccine program, leaving the patient preference. As of 30.04.2021, Turkey has risen to sixth place among the countries that have applied the most COVID-19 vaccine globally, and it has applied the first dose to $13,715,749$ people and the second dose to $9,107,089$ people $(9,10)$. 
In this study, the general characteristics of the patients who were vaccinated with CoronaVac or BNT162b2 vaccines in Sakarya Province of Turkey and administered to Sakarya Training and Research Hospital (SEAH) emergency room (ER) were examined. It is aimed to define the demographic structure of patients admitted to the ER with COVID-19 symptoms after vaccination, hospitalization status, length of stay (LoS), and mortality. In this way contribute to the current medical literature with a limited number of publications on this subject.

\section{MATERIAL AND METHOD}

The study protocol was approved by the Sakarya University Faculty of Medicine Non-Interventional Ethics Committee (Date: 28.04.2021, Decision No: 310). All procedures were carried out in accordance with the ethical rules and the principles of the Declaration of Helsinki.

\section{Research Type}

This research is a retrospective, cross-sectional and descriptive study. Furthermore, it includes the period between 15.01.2021 and 30.04.2021.

The study sample was the patients who presented to the SEAH adult ER with COVID-19 symptoms after being vaccinated with CoronaVac or BNT162b2. The study population was the vaccinated patients who applied to the ER with the findings of COVID-19.

\section{Definitions}

CoronaVac is an inactive vaccine, and BNT162b2 is an mRNA vaccine, and these vaccines are applied in two doses. By the Ministry of Health's vaccine application strategy, vaccines are applied in two doses at four-week intervals (11). Primarily, healthcare workers, people living in elderly nursing homes, and older adults over 65 were vaccinated in Turkey (11).

Fever, cough, dyspnea, sore throat, headache, myalgia, loss of taste and smell, or diarrhea have been affirmed as COVID-19 symptoms (12). Rt-PCR was analyzed by taking oropharyngeal and nasopharyngeal combined swabs in all cases with COVID-19 symptoms. Only patients with a positive Rt-PCR test were recognized positive in the study.

\section{Inclusion Criteria}

Among patients vaccinated with at least one dose of CoronaVac or BNT162b2, the following were included in the study:

- Patients aged 18 and over,

- Patients with at least one COVID-19 symptom,

- Patients admitted to the XEAH ER,
- Patients whose information could be accessed fully from the hospital automation system.

\section{Exclusion Criteria}

- Patients younger than 18 years old,

- Pregnant patients,

- COVID-19 patients who have never been vaccinated with COVID-19 vaccines,

- Patients who applied to the ER with a complaint other than COVID-19 symptoms,

- Patients whose information could not be fully reached were excluded from the study.

\section{Data Collection}

The data of the cases that applied to the XEAH ER during the study period was reached from the hospital automation system and patient files. Patients' age, gender information, the name of the applied vaccine, the number of vaccine's dose, the time between vaccination and admission to the ER, Rt-PCR positivity after vaccination, hospitalization status, length of stay (LoS) in hospital, and mortality status of the inpatients were retrospectively scanned.

\section{Statistical Analysis}

The collected data were analyzed with the IBM SPSS Statistics for Windows, Version 21.0 (IBM Corp. Released 2012, Armonk, NY: IBM Corp.). Skewness and Kurtosis results were verified to be in the range of $-2 /+2$ for the data's normal distribution (13). Chi-square test was utilized for comparison of categorical data, and resulted with $\mathrm{p}<0.05$ were accepted statistically meaningful.

An independent t-test was applied to compare two independent data groups that were normally distributed, and results with $\mathrm{p}<0.05$ were considered significant.

\section{RESULTS}

An 887 COVID-19 vaccinated patients who applied to ER with COVID-19 symptoms were included in the study. Of these, 383 (42.2\%) were male, and 504 (56.8\%) were female. The mean age of the patients was $52( \pm 18.6)$ years, the median value was 56 , and the age range was between 20-94 years.

The number of single-dose vaccinated patients admitted to the ER was 696 (78.5\%), and the number of two doses vaccinated patients admitted was 191 (21.5\%). The Coronavac vaccine was applied to $755(85.1 \%)$ of the patients; the BNT162b2 vaccine was also applied to 132 (14.9\%).

In 317 (35.7\%) cases, Rt-PCR positivity was detected in the ER application after vaccination. Of the total patients, 86 (9.7\%) were hospitalized; furthermore, 14 patients $(1.4 \%)$ died during the treatment in the hospital. 
The mean time between vaccination and application to ER was $25( \pm 21.9)$ days, and the median value was 18 days. This period was $28.1( \pm 18)$ days in two-dose vaccinated patients, and the median value was 26 days. The time to apply to ER was longer in those who were vaccinated with two doses.

The patients's gender and mean age, post-vaccination Rt-PCR positivity, hospitalization and mortality status were compared in Table. Accordingly, no significant relationship was observed between the patients' gender and their PCR positivity or hospitalization status (respectively; $\mathrm{x} 2=1.665, \mathrm{SD}=1, \mathrm{p}=0.197$ and $\mathrm{x} 2=1.806, \mathrm{SD}=1, \mathrm{p}=0.179)$. There was a significant difference between the genders and the mortality status that mortality was higher in male patients $(\mathrm{x} 2=4.627$, $\mathrm{SD}=1, \mathrm{p}=0.031)$. According to the independent t-test results, Rt-PCR positive patients' mean age (mean $=57$, $\mathrm{SD}=17$ ) was found to be significantly higher than RtPCR negative patients' mean age $($ Mean $=49, \mathrm{SD}=18.9)$ [t(714)=-5.69, $\mathrm{p}=0.001]$. In addition, hospitalized patients' mean age (mean $=69, \mathrm{SD}=9.9)$ was seen to be significantly higher than the outpatients (Mean $=50$, $\mathrm{SD}=18.3)[\mathrm{t}(157)=-15, \mathrm{p}<0.001]$. Also, the mean age of the patients with mortality (mean $=71, \mathrm{SD}=11.9$ ) was found to be statistically significantly higher than the surviving patients (mean $=52, \mathrm{SD}=18.5)[\mathrm{t}(14)=-5.87$, $\mathrm{p}<0.001]$.

Of those vaccinated with a single dose of Coronavac vaccine, $9(1.6 \%)$ died, while two $(1.1 \%)$ of those vaccinated with two doses. Similarly, no significant difference was observed in hospitalization status and Rt-PCR test positivity between those vaccinated with a single or two doses of the Coronavac vaccine (respectively; $\mathrm{x} 2=0.337, \mathrm{SD}=1, \mathrm{p}=0.561 ; \mathrm{x} 2=0.863$, $\mathrm{SD}=1, \mathrm{p}=0.353)$.

When 14 ex-cases were examined, it was noticed that all of them were Rt-PCR positive, 12 of them were vaccinated in a single dose, and they presented to the hospital after an average of $20.5( \pm 14.2)$ days after the first dose of vaccination. In addition, the average LoS in the hospital was determined to be $8( \pm 4.1)$ days. 11 of dead patients were vaccinated with the CoronaVac vaccine and 3 with the BNT162b2 vaccine, but it was affirmed that there was no notable variation in mortality between vaccines $(\mathrm{p}=0.450)$.

\section{DISCUSSION}

Studies on hospital admissions of patients with the COVID-19 vaccine are limited in the medical literature. In a study conducted in the same region in the first months of the pandemic, 169 COVID-19 patients admitted to the ER and hospitalized were examined, and the average age of the patients was $64.3( \pm 17.6)$ years (14). Additionally, in the same study, 56.2\% of the hospitalized patients were reported to be male (14). The average age of the hospitalized patients in our study was 69.3 years ( \pm 9.4 years), and $53.8 \%$ were women. Accordingly, it can be thought that the average age of the patients hospitalized from the ER after vaccination increased, and the rate of hospitalization of women increased. However, it can be said that giving priority to those aged 65 and over in the vaccination program causes the average age to be high. However, as of $26.04 .2021,47 \%$ of COVID-19 patients who were recently hospitalized in the USA were 60 years old and over. Moreover, $56 \%$ of these cases were female, consistent with our study results (15).

Our study observed that the Rt-PCR positivity rate of vaccinated patients who applied to the ER with COVID-19 symptoms was $35.7 \%$. This Rt-PCR positivity rate may appear to be high compared to a vaccinated population. However, the rate of two-dose vaccinated Rt-PCR positive patients was among all patients was $8.3 \%$.

Among all vaccinated patients, the hospitalization rate of those who applied to the ER was $9.7 \%$, and the mortality rate was $1.58 \%$. The mortality rate among hospitalized patients was found to be $16.3 \%$. In a study conducted in the USA, it was reported that $21 \%$ of COVID-19 patients who were hospitalized resulted in mortality (16). In addition, Wenjie et al. found that the mortality rate in hospitalized COVID-19 cases was 25\% (17).

\begin{tabular}{|c|c|c|c|c|c|c|c|c|c|c|c|c|c|c|c|c|}
\hline \multirow{3}{*}{\multicolumn{2}{|c|}{ Parameter }} & \multicolumn{5}{|c|}{ Rt-PCR } & \multicolumn{5}{|c|}{ Hospitalization } & \multicolumn{5}{|c|}{ Mortality } \\
\hline & & \multicolumn{2}{|c|}{ Positive } & \multicolumn{2}{|c|}{ Negative } & \multirow{2}{*}{$\begin{array}{l}\text { Statistical } \\
\text { value }\end{array}$} & \multicolumn{2}{|c|}{ Yes } & \multicolumn{2}{|c|}{ No } & \multirow{2}{*}{$\begin{array}{l}\text { Statistical } \\
\text { value }\end{array}$} & \multicolumn{2}{|c|}{ Ex } & \multicolumn{2}{|c|}{ Alive } & \multirow{2}{*}{$\begin{array}{l}\text { Statistical } \\
\text { value }\end{array}$} \\
\hline & & n & $\%^{\mathrm{a}}$ & $\mathbf{N}$ & $\%^{\mathrm{a}}$ & & $\mathrm{n}$ & $\%^{a}$ & n & $\%^{\mathrm{a}}$ & & $\mathbf{n}$ & $\%^{a}$ & n & $\%^{a}$ & \\
\hline \multirow{2}{*}{ Gender } & Male & 146 & 16.5 & 237 & 26.7 & \multirow{2}{*}{$\mathrm{p}=0.197^{\mathrm{b}}$} & 43 & 4.8 & 340 & 38.3 & \multirow{2}{*}{$0.179^{\mathrm{b}}$} & 10 & 1.1 & 373 & 42.1 & \multirow{2}{*}{$0.031^{\mathrm{b}}$} \\
\hline & Female & 171 & 19.3 & 333 & 37.5 & & 43 & 4.8 & 461 & 52 & & 4 & 0.5 & 500 & 56.4 & \\
\hline \multirow{2}{*}{ Doses } & 1 & 243 & 27.4 & 453 & 51.1 & \multirow{2}{*}{$\mathrm{p}=0.328^{\mathrm{b}}$} & 64 & 7.2 & 632 & 71.3 & \multirow{2}{*}{$\mathrm{p}=0.337^{\mathrm{b}}$} & 12 & 1.4 & 684 & 77.1 & \multirow{2}{*}{$p=0.746^{c}$} \\
\hline & 2 & 74 & 8.3 & 117 & 13.2 & & 22 & 2.5 & 169 & 19.1 & & 2 & 0.2 & 189 & 21.3 & \\
\hline \multirow{2}{*}{$\begin{array}{l}\text { Vaccine } \\
\text { Name }\end{array}$} & CoronaVac & 269 & 30.3 & 486 & 54.8 & \multirow{2}{*}{$\mathrm{p}=0.871^{\mathrm{b}}$} & 79 & 8.9 & 676 & 76.2 & \multirow{2}{*}{$\mathrm{p}=0.065^{\mathrm{b}}$} & 11 & 1.2 & 744 & 83.9 & \multirow{2}{*}{$\mathrm{p}=0.450^{\mathrm{c}}$} \\
\hline & BNT162b2 & 48 & 5.4 & 84 & 9.5 & & 7 & 0.8 & 125 & 14.1 & & 3 & 0.3 & 129 & 14.5 & \\
\hline \multicolumn{2}{|c|}{ Average Age } & \multicolumn{2}{|c|}{57} & \multicolumn{2}{|c|}{49} & $\mathrm{p}=0.001^{\mathrm{d}}$ & \multicolumn{2}{|c|}{69} & \multicolumn{2}{|c|}{50} & $\mathrm{p}=0.001^{\mathrm{d}}$ & \multicolumn{2}{|c|}{71} & \multicolumn{2}{|c|}{52} & $\mathrm{p}=0.001^{\mathrm{d}}$ \\
\hline
\end{tabular}

a: It is the ratio of all vaccinated patients, ${ }^{\text {}}$ : Pearson Chi-Square test, ${ }^{c}$ : Fisher's Exact test, d: Independent t-test 
When compared with the mortality rates of hospitalized Covid-19 patients in the literature, it can be said that the mortality rate of vaccinated patients was few.

Patients vaccinated with the BNT162b2 vaccine appear to have fewer ER admissions, hospitalizations, and lower mortality than those vaccinated with the Coronavac vaccine. This situation is controversial whether the Coronavac vaccine was applied more in the community during the study period or whether the BNT162b2 vaccine was more protective than Coronavac. There is a need for further studies on this subject as vaccination becomes more widespread in the population.

\section{Limitations}

The study included patients who applied to SEAH ER as a single-center, and the fact that the patients may have applied to another hospital was the limitation of the study.

\section{CONCLUSION}

People who are vaccinated with the COVID-19 vaccine continue to have hospital admissions with COVID-19 symptoms. Rt-PCR positivity, need for hospitalization, and mortality may continue to be seen in vaccinated individuals. However, it will be possible to have a more precise opinion with new studies.

\section{ETHICAL DECLARATIONS}

Ethics Committee Approval: The study protocol was approved by the Sakarya University Faculty of Medicine Non-Interventional Ethics Committee (Date: 28.04.2021, Decision No: 310).

Informed Consent: Because the study was designed retrospectively, no written informed consent form was obtained from patients.

Referee Evaluation Process: Externally peer-reviewed.

Conflict of Interest Statement: The authors have no conflicts of interest to declare.

Financial Disclosure: The authors declared that this study has received no financial support.

Author Contributions: All of the authors declare that they have all participated in the design, execution, and analysis of the paper, and that they have approved the final version.

\section{REFERENCES}

1. WHO announces COVID-19 outbreak a pandemic [Internet]. World Health Organization; 2020 [cited 2020 Apr 11]. Available from:http://www.euro.who.int/en/health-topics/healthemergencies/coronavirus-COVID-19/news/news/2020/3/whoannounces-COVID-19-outbreak-a-pandemic

2. Durmuş E, Güneysu F. Effect of COVID-19 on the admissions to the adult emergency department. J Contemp Clin Pract 2020; 6 : 58-63.
3. Trivedi N, Verma A, Kumar D. Possible treatment and strategies for COVID-19: review and assessment. Eur Rev Med Pharmacol Sci 2020; 24: 12593-608.

4. Bhavana V, Thakor P, Singh SB, Mehra NK. COVID-19: Pathophysiology, treatment options, nanotechnology approaches, and research agenda to combating the SARS-CoV2 pandemic. Life Sci 2020; 261: 118336.

5. Zhao J, Zhao S, Ou J, et al. COVID-19: Coronavirus vaccine development updates. Front Immunol 2020; 11: 602256.

6. Pan D, Mudalige NL, Sze S, et al. The new UK SARS-CoV-2 variant and lockdown-causes and consequences. Clin Med Lond Engl 2021; 21: e295.

7. Naqvi AAT, Fatima K, Mohammad T, et al. Insights into SARSCoV-2 genome, structure, evolution, pathogenesis and therapies: Structural genomics approach. Biochim Biophys Acta BBA-Mol Basis Dis. 2020; 1866: 165878.

8. Hodgson SH, Mansatta K, Mallett G, Harris V, Emary KRW, Pollard AJ. What defines an efficacious COVID-19 vaccine? A review of the challenges assessing the clinical efficacy of vaccines against SARS-CoV-2. Lancet Infect Dis 2021; 21: e26-35.

9. [T.R. Ministry of Health COVID-19 Vaccine Information Platform] T.C. Sağlık Bakanlığı COVID-19 Așısı Bilgilendirme Platformu [İnternet]. Turkey Vaccine Table. 2021 [cited 2021 Apr 30]. Available from: https://COVID19asi.saglik.gov.tr/

10.Coronavirus (COVID-19) Vaccinations-Statistics and Research [Internet]. Our World in Data. 2021 [cited 2021 Apr 30]. Available from: https://ourworldindata.org/COVID-vaccinations

11. [COVID-19 Vaccine National Implementation Strategy] COVID-19 Aşısı Ulusal Uygulama Stratejisi [İnternet]. [T.R. Ministry of Health COVID-19 Vaccine Information Platform] T.C. Sağlık Bakanlığı COVID-19 Aşısı Bilgilendirme Platformu. 2021 [cited 2021 Apr 30]. Available from: https://COVID19asi. saglik.gov.tr/TR-77706/COVID-19-asisi-ulusal-uygulamastratejisi.html

12. [COVID-19 (Sars-Cov-2 Infection) General Information, Epidemiology And Diagnosis] COVID-19 (Sars-Cov-2 Enfeksiyonu ) Genel Bilgiler, Epidemiyoloji ve Tanı [İnternet]. T.C. Sağlık Bakanlığı; 2020 [cited 2021 Apr 30]. Available from: https://COVID19.saglik.gov.tr/Eklenti/39551/0/COVID-19rehbe rigenelbilgilerepidemiyolojivetanipdf.pdf

13. George D, Mallery P. IBM SPSS statistics 25 step by step: a simple guide and reference. Fifteenth edition. New York; London: Routledge, Taylor \& Francis Group; 2019. 404 p.

14. Guneysu F, Guner NG, Erdem AF, Durmus E, Durgun Y, Yurumez Y. Can COVID-19 mortality be predicted in the emergency room? J Coll Physicians Surg Pak 2020; 31: 928-32.

15. Hospitalization Demographics | NC DHHS COVID-19 [Internet]. 2021 [cited 2021 May 1]. Available from: https://COVID19. ncdhhs.gov/dashboard/hospitalization-demographics

16. Richardson S, Hirsch JS, Narasimhan M, et al. Presenting characteristics, comorbidities, and outcomes among 5700 patients hospitalized with COVID-19 in the New York City area. JAMA 2020; 323: 2052. 